УДК 340.132.626

Е. В. Пирмаев

Верховный Суд Республики Бурятия, г. Улан-Удэ, Российская Федерация

\title{
ВИДЫ СУДЕБНОГО ТОЛКОВАНИЯ
}

\begin{abstract}
АНнотАция. В статье анализируется судебное толкование как самостоятельный вид толкования права. Отмечается его особое место среди других видов толкования. Рассматриваются основные классификации, за основу которых берутся такие критерии, как объект и субъект толкования. Описываются основные виды судебного толкования в зависимости от субъекта толкования. Предлагается авторская классификация видов судебного толкования по субъектам толкования, которая включает в себя такие виды, как аутентическое нормативное судебное толкование; аутентическое казуальное судебное толкование; легальное нормативное судебное толкование; легальное казуальное судебное толкование. Особое внимание уделяется официозному судебному толкованию. Представлена также классификация видов неофициального судебного толкования. Делается вывод, что неофициальное судебное толкование подразделяется на профессиональное и доктринальное и может быть только компетентным. В заключении сконцентрированы основные выводы, к которым пришел автор относительно видов судебного толкования.

кЛючЕВЫЕ СЛОВА. Толкование права; судебное толкование; проблемы классификации; судебное толкование по объему; судебное толкование по субъектам.

ИНФОРМАЦИЯ О СТАТЬЕ. Дата поступления 28 августа 2016 г.; дата принятия к печати 13 сентября 2016 г.; дата онлайн-размещения 30 сентября 2016 г.
\end{abstract}

Ye. V. Pirmayev

Supreme Court of Republic of Buryatia,

Ulan-Ude, Russian Federation

\section{TYPES OF COURT INTERPRETATION}

\begin{abstract}
The article analyzes court interpretation as an independent type of law interpretation. It notes its specific place among other types of interpretations. It considers main classifications, taking as a basis such criteria as object and subject of interpretation. It describes main types of court interpretation depending on the subject of interpretation. It offers an author's classification of court interpretations in terms of subjects of interpretation which includes such types as authentic normative interpretation; authentic casual court interpretation; legal normative court interpretation; legal casual court interpretation. A special attention is given to official court interpretation. It also presents a classification of types of non-official court interpretation and draws a conclusion that unofficial court interpretation is divided into professional and doctrinal ones and can be only competent. In the end, it concentrates main conclusions in regard of types of court interpretation.

KEYWORDS. Interpretation of law; court interpretation; problems of classification; court interpretation in terms of amount; court interpretation in terms of subjects.

ARTICLE INFO. Received August 28, 2016; accepted September 13, 2016; available online September 30, 2016.
\end{abstract}

Судебное толкование - это интеллектуальная деятельность, осуществляемая судом, направленная на уяснение и разъяснение истинного смысла правового предписания, результатом которой является судебное решение.

Вопрос о судебном толковании постоянно находится в поле зрения российских юристов, начиная со второй половины XIX в. [1, с. 1-62] и до наших дней [2, с. 72-78].

(C) E. В. Пирмаев, 2016

\section{Baikal Research Journal}


Выделение видов - это, прежде всего, проблемы классификации. Соблюдение правил формальной логики в целом и правил классификации в частности - необходимые условия для четкого выделения видов любого явления. Одна из главных задач при этом - выбор основания, по которому будет осуществляться классификация. Как справедливо отмечает С. С. Розова, ведущий специалист в области теории классификации, «те или иные требования к классификации, как правило, модифицируются в требования к основанию, и удачность его выбора представляется центральным моментом, определяющим собой успех построения классификации» [3, с. 18].

В юридической литературе, когда речь идет о видах толкования, классификация осуществляется по двум основным критериям - объем толкования и субъект толкования.

Что касается толкования права по объему, то здесь существует достаточно устоявшаяся позиция, согласно которой выделяется три вида толкования - буквальное (адекватное), распространительное (расширительное) и ограничительное [4, с. 481-483; 5, с. 306-308; 6, с. 283].

Дискуссии, которые возникали по этому поводу, сводилось к тому, что, во-первых, оспаривалось целесообразность выделение такого вида, как буквальное толкование, и, во-вторых, существовал определенный спор о терминах. Так, Н. Д. Дурманов полагал, что нельзя считать буквальное или адекватное толкование видом толкования по объему, поскольку при этом только констатируется, что слова и смысл закона полностью совпадают. По его мнению, поскольку в результате исследования текста закона оказывается, что объем толкуемого закона остается точно таким же, как и до толкования, то нет оснований выделять буквальное толкование. Он же возражал против термина «расширительное толкование» и считал, что желательно пользоваться термином «распространительное толкование» [7, с. 304-305].

Перенося общепринятую классификацию на судебное толкование, можно выделить три вида судебного толкования по объему - адекватное (буквальное), распространительное (расширительное) и ограничительное судебное толкование.

Что же касается толкования права по субъектам, то здесь спор идет не только о терминах, но и о видах толкования. Общепризнано, что изначально по этому основанию толкование делится на официальное толкование (исходящее от специально уполномоченного органа или должностного лица, и результат такого толкования обязателен) и неофициальное толкование (исходящее от любого субъекта, результат которого необязателен). Официальное толкование в свою очередь подразделяется на аутентическое толкование (исходящее от того же органа, который издал толкуемый акт) и легальное (делегированное) толкование (исходящее от субъекта, который сам не участвовал в создание данного акта, но обладает правом официального толкования).

Термины «легальное толкование» и «делегированное толкование» отождествляются, но оба представляются неудачными. Термин «легальное толкование» наводит на мысль, что может быть и нелегальное толкование. Кроме того, слово «legal» в переводе с английского означает «юридический, юридическое», а любое толкование права по своей природе является юридическим. Когда употребляется термин «делегированное толкование», то делегирование здесь понимается не как передача полномочий по официальному толкованию от одного органа другому, а как наделение полномочиями по официальному толкованию, что строго говоря, делегированием не является.

Признавая всю условность терминологии, в данной статье будем оперировать термином «легальное толкование».

Кроме того, в юридической литературе официальное толкование, как правило, делится на нормативное толкование (рассчитанное на многократное применение, на

\section{Baikal Research Journal}

электронный научный журнал Байкальского государственного университета 
неограниченное количество однородных случаев) и казуальное толкование (рассчитанное на конкретный случай).

Представляется неверным связывать нормативное и казуальное толкование только с официальным толкованием. Здесь как раз и происходит смешение критерия классификации, на важность которого указывала С. С. Розова [3]. Когда выделяются аутентическое и легальное толкование, то основанием классификации действительно является субъект толкования. Когда же речь идет о нормативном и казуальном толковании, то критерий классификации другой - это распространимость толкования (на неограниченное количество однородных случаев либо на один конкретный случай).

Подробная классификация видов судебного толкования будет дана далее, но изначально следует отметить, что судебное толкование может быть официальныл и неофициальным, аутентическил и легальным, норлативныл и казуальныл. В связи с этим нельзя согласиться с мнением В. В. Лазарева, который считает, что судебное толкование может быть только казуальным [8, с. 100]. Толкование, которое дают высшие судебные инстанции в постановлениях пленумов, носит нормативный характер.

В юридической науке и ранее отмечалось, что нормативное и казуальное толкование могут быть как официальным, так и неофициальным [9, с. $248 ; 10$, с. 6-7]. Думается, что следует полностью поддержать такую позицию.

В связи с этим допустимо выделение таких видов официального толкования, как:

- аутентическое нормативное;

- аутентическое казуальное;

- легальное нормативное;

- легальное казуальное.

Если не вникать в спор о терминах, то следует признать, что первый, второй и четвертый виды давно уже существуют в интерпретационной практике. Например, принятие Правительством Российской Федерации инструкции, разъясняющей собственное постановление (первый вид). постановление Пленума Верховного Суда Российской Федерации, разъясняющее содержание отдельных статей нормативных актов (третий вид), определение коллегии по гражданским (или уголовным) делам Верховного Суда Российской Федерации по конкретному делу, разъясняющее судам нижестоящих инстанций как нужно было применить конкретные статьи конкретного нормативного акта по данному делу (четвертый вид).

Если же рассматривать данные виды толкования через призму судебного толкования, то аутентическое нормативное толкование можно отнести к судебному только применительно к практике Конституционного Суда Российской Федерации. Это единственный орган в судебной системе Российской Федерации, который бесспорно является субъектом правотворчества. С некоторыми оговорками сюда же можно отнести конституционные (уставные) суды субъектов Федерации. Оговорка связана с тем, что законы субъектов Федерации неоднозначно регулируют вопрос о компетенции конституционных (уставных) судов.

Легальное нормативное толкование занимает большое место в практике Верховного Суда Российской Федерации (а ранее и Высшего Арбитражного Суда Российской Федерации), а легальное казуальное толкование - в практике всех судов.

Остается открытым вопрос об аутентическом казуальном толковании.

И. А. Минникес полагает, что нельзя дать однозначную оценку попытке выделить такой вид толкования, как аутентическое казуальное толкование. Автор не соглашается с мнением С. Ю. Болонина, который относит к этому виду толкования акты судов кассационных и надзорных инстанций [11, с. 28-35], справедливо полагая, что в данном случае мы имеем дело с легальным толкованием. В тоже вре-

\section{Baikal Research Journal}


мя И. А. Минникес соглашается с Я. Н. Колоколовым, который говорит о том, что аутентическое казуальное толкование может осуществляться Конституционным Судом Российской Федерации, когда он толкует свои же ранее принятые решения [12]. Думается, что с позицией И. А. Минникеса следует согласиться [10, с. 4-11].

Действующее законодательство позволяет судам общей юрисдикции и арбитражным судам прибегать к аутентическому казуальному толкованию. Об этом свидетельствует содержание ст. 179 Арбитражного процессуального кодекса РФ, ст. 202 Гражданского процессуального кодекса РФ, ст. 185 Кодекса административного судопроизводства РФ, которые регулируют порядок разъяснения решений суда. В них говорится, что в случае неясности суд, принявший решение, по заявлению лиц, участвующих в деле, вправе разбяснить решение без изленения его содержания. - а это и есть аутентическое казуальное судебное толкование.

Противники данной точки зрения говорят о том, что в данном случае толкуется не норма права, а правоприменительный акт. Однако никакого противоречия здесь не усматривается, так как объектом толкования может быть любой правовой акт, а не только нормативный.

Исходя из сказанного, можно выделить следующие виды судебного толкования: аутентическое нормативное судебное толкование; аутентическое казуальное судебное толкование; легальное нормативное судебное толкование; легальное казуальное судебное толкование.

Идею об аутентическом казуальном толковании поддерживает и А. Ф. Черданцев: «Если тот или иной орган может давать толкование своих нормативных актов к целой категории дел, то тем более он имеет право толковать свои акты и применительно к конкретному делу, если такая необходимость возникает. Таким образом, можно говорить об аутентическом казуальном толковании» [6, с. 294]. Однако в приведенном примере речь идет об аутентическом казуальном толковании, которое нельзя отнести к судебному толкованию.

И. А. Минникес высказывает схожую позицию, но подходит к этому вопросу с позиций индивидуального правового регулирования [13, с. 62].

Некоторыми авторами выделяется такой вид толкования, как официозное толкование. Так, Ф. Н. Фаткуллин писал о том, что официозное толкование осуществляется специально уполномоченными на то органами по определенным категориям правовых норм, независимо от того, кем они изданы [9, с. 249]. Однако при таком подходе совершенно непонятно: чем этот вид толкования отличается от аутентического или легального.

Иначе подходит к этому вопросу А. Ф. Черданцев. Он считает, что официозное толкование дается официальными государственными органами, но формально не имеет обязательного значения. Такое толкование содержится в обобщениях и обзорах судебной практики, информационных письмах, рассылаемых центральными государственными органами. Официозное толкование может быть и казуальным. Оно дается должностными лицами государственных органов, но не облекается в надлежащую юридическую форму. В качестве примера автор приводит толкование какого-либо закона применительно к конкретному случаю, даваемое прокурором при приеме граждан, рассмотрении письменной жалобы и т. д. [6, с. 294-295].

Думается, с мнением А. Ф. Черданцева следует согласиться. Такой же деятельностью, наряду с прокуратурой и другими юрисдикционными органами, могут заниматься и суды. В развитие этой позиции можно сделать вывод, что судебное толкование может быть официозныл, при этом как нормативным, так и казуальным.

Ф. Н. Фаткуллин, наряду с официозным, выделял еще ведомственное толкование, которое осуществляется центральным руководством того или иного ведомства, когда оно дает официальные ответы на запросы подведомственных организаций и

\section{Baikal Research Journal}

электронный научный журнал Байкальского государственного университета 
предприятий по поводу трактовки и применения отдельных правительственных нормативных актов. Сила такого толкования ограничивается сферой деятельности данного ведомства [9, с. 249-250]. То, что ведомства дают такое толкование, сомнений не вызывает, но приведенный пример вписывается в классическую схему легального толкования и не убеждает в том, что ведомственное толкование является отдельным видом толкования. Отличие здесь только в субъекте.

Неофициальное толкование принято подразделять на обыденное, профессиональное и доктринальное (научное). Это устоявшаяся точка зрения, которая нашла отражение даже в учебной литературе [14, с. 304]. Ф. Н. Фаткуллин выделял еще такой вид неофициального толкования, как специально-пояснительное толкование, которое дается в различных комментариях к законодательству, составляемых научными и практическими работниками в области права [9, с. 250]. Однако думается, что вряд ли имеются основания для выделения этого толкования в отдельный вид. По своей природе это тоже доктринальное толкование.

Л. В. Соцуро выделяется еще такой вид неофициального толкования, как компетентное толкование. Он отмечает, что этот вид толкования имеет тесную связь с профессиональным и доктринальным толкованием, «однако интересы строгой юриспруденции требуют четкого разграничения данных явлений на понятийном уровне» $[15$, с. 42$]$. Соглашаясь с автором в необходимости такого разграничения, думается, что компетентное толкование является родовым понятием для профессионального и доктринального толкования, которые в свою очередь являются видами компетентного толкования.

Судебное толкование является только компетентным. И теоретически, и практически невозможно представить, чтобы судебное толкование было обыденным. Как представляется, неофициальное судебное толкование, являясь компетентным, может быть профессиональныли и доктринальнылм.

Подводя итоги сказанному, думается, можно выделить следующие виды судебного толкования:

- по объему толкования - адекватное (буквальное), распространительное (расширительное) и ограничительное судебное толкование;

- по субъекту толкования и степени обязательности - официальное, официозное и неофициальное судебное толкование;

- по характеру содержащихся предписаний - нормативное и казуальное судебное толкование.

И в развитие данных классификаций:

- виды официального судебного толкования - аутентическое нормативное судебное толкование; аутентическое казуальное судебное толкование; легальное нормативное судебное толкование; легальное казуальное судебное толкование;

- виды неофициального судебного толкования - компетентное судебное толкование, которое подразделяется на профессиональное и доктринальное судебное толкование.

\section{Список использованной литературы}

1. Градовский А. О судебном толковании законов по русскому праву / А. Градовский // Журнал гражданского и уголовного права. - 1874. - Кн. 1 : Январь и февраль. - С. 1-62.

2. Гук П. А. Судебное толкование норм права / П. А. Гук // Журнал российского права. 2016. - № 8. - C. $72-78$. - DOI : $10.12737 / 20905$.

3. Розова С. С. Классификационная проблема в современной науке / С. С. Розова. - Новосибирск : Наука, 1986.- 224 с.

4. Марксистско-ленинская общая теория государства и права: Социалистическое право / А. М. Айзенберг, Н. Г. Александров, С. С. Алексеев, Е. А. Лукашева [и др.]. - М. : Юрид. лит., 1973. -647 с.

\section{Baikal Research Journal}


5. Алексеев С. С. Общая теория права : курс в 2-х т. / С. С. Алексеев. - М. : Юрид. лит., 1982. - T. 2. - $360 \mathrm{c.}$

6. Черданцев А. Ф. Толкование права и договора: учеб. пособие / А. Ф. Черданцев. - М. : Юнити-Дана, 2003. - 381 с.

7. Дурманов Н. Д. Советский уголовный закон / Н. Д. Дурманов. - М. : Изд-во Моск. унта, 1967. - $319 \mathrm{c.}$

8. Лазарев В. В. Применение советского права / В. В. Лазарев. - Казань : Изд-во Казан. ун-та, $1972 .-200$ с.

9. Фаткуллин Ф. Н. Проблемы теории государства и права: курс лекций / Ф. Н. Фаткуллин. - Казань : Изд-во Казан. ун-та, 1987. - 336 с.

10. Минникес И. А. Казуальное толкование: проблемы теории и практики / И. А. Минникес // Академический юридический журнал. - 2016. - № 1. - С. 4-11.

11. Болонин С. Ю. Значение актов официального казуального правотолкования в правоприменительной деятельности / С. Ю. Болонин // Ученые записки Казанского государственного университета. Сер. Гуманитарные науки. - 2010. - Т. 152, кн. 4. - С. 28-35.

12. Колоколов Я. Н. Аутентическое толкование норм права: поиск новых парадигм / Я. Н. Колоколов. - М. : Юрлитинформ, 2010. - 376 с.

13. Минникес И. А. Индивидуальные правовые акты (к проблеме индивидуального правового регулирования) / И. А. Минникес // Известия Иркутской государственной экономической академии. - 2006. - № 5 (50). - С. 59-62.

14. Морозова Л. А. Теория государства и права : учебник / Л. Н. Морозова. - М. : Юристъ, 2004. - $414 \mathrm{c.}$

15. Соцуро Л. В. Неофициальное толкование норм права : учеб. пособие / Л. В. Соцуро. М. : Профобразование, 2000. - 112 с.

\section{References}

1. Gradovsky A. On court interpretation of legislation in Russian law. Zhurnal grazhdanskogo i ugolovnogo prava = Journal of Civil and Criminal Law, 1874, book 1, pp. 1-62. (In Russian).

2. Guk P. A. Judicial Interpretation of Law. Zhurnal rossiyskogo prava = Journal of Russian $L a w, 2016$, no. 8, pp. 72-78. DOI: 10.12737/20905. (In Russian).

3. Rozova S. S. Klassifikatsionnaya problema v sovremennoi nauke [Classification problem in modern science]. Novosibirsk, Nauka Publ., 1986. 224 p.

4. Aizenberg A. M., Aleksandrov N. G., Alekseyev S. S., Lukasheva E. A. at al. Marksistsko-leninskaya obshchaya teoriya gosudarstva i prava: Sotsialisticheskoe parvo [Marx-Lenin general theory of state and law]. Moscow, Yuridicheskaya Literature Publ., 1973. 647 p.

5. Alekseyev S. S. Obshchaya teoriya prava [General Theory of Law]. Moscow, Yuridicheskaya Literature Publ., 1982. Vol. 2. 360 p.

6. Cherdantsev A. F. Tolkovanie prava i dogovora [Interpretation of law and contract]. Moscow, Yuniti-Dana Publ., 2003. 381 p.

7. Durmanov N. D. Sovetskii ugolovnyi zakon [Soviet Criminal Law]. Lomonosov Moscow State University Publ., 1967. 319p.

8. Lazarev V. V. Primenenie sovetskogo prava [Use of Soviet Law]. Kazan State University Publ., 1972. 200 p.

9. Fatkullin F. N. Problemy teorii gosudarstva i prava [Problems of theory of state and law]. Kazan' State University Publ., 1987. 336 p.

10. Minnikes I. A. Casual interpretation: theory and practice problems. Akademicheskii yuridicheskii zhurnal = Academic Juridical Journal, 2016, no. 1, pp. 4-11. (In Russian).

11. Bolonin S. Yu. Significance of acts of official casual law interpretation in law enforcement activity. Uchenye zapiski Kazanskogo gosudarstvennogo universiteta. Seriya: Gumanitarnye nauki $=$ Proceedings of Kazan University. Humanities Series, 2010, vol. 152, book 4, pp. 28-35. (In Russian).

12. Kolokolov Ya. N. Autenticheskoe tolkovanie norm prava: poisk novykh paradigm [Authentic interpretation of norms of law: in search for new paradigms]. Moscow, Yuridicheskaya Literature Publ., 2010. 376 p.

13. Minnikes I. A. Individual legal acts (about the problem of individual legal regulation). Izvestiya Irkutskoi gosudarstvennoi ekonomicheskoi akademii = Bulletin of Irkutsk State Economics Academy, 2006, no. 5 (50), pp. 59-62. (In Russian).

\section{Baikal Research Journal}


14. Morozova L. A. Teoriya gosudarstva i prava [Theory of State and Law]. Moscow, Yurist" Publ., 2004. 414 p.

15. Sotsuro L. V. Neofitsial'noe tolkovanie norm prava [Unofficial interpretation of norms of law]. Moscow, Profobrazovanie Publ., 2000. 112 p.

\section{Информация об авторе}

Пирлаев Евгений Владилирович - судья, Верховный Суд Республики Бурятия, 670000, г. Улан-Удэ, ул. Коммунистическая, 51, e-mail: pirmaev@mail.ru.

\section{Author}

Yevgeny V. Pirmayev - Judge, Supreme Court of Republic of Buryatia, 51 Kommunisticheskaya St., 670000, Ulan-Ude, Russian Federation; e-mail: pirmaev@mail.ru.

\section{Библиографическое описание статьи}

Пирмаев Е. В. Виды судебного толкования / Е. В. Пирмаев // Baikal Research Journal. -

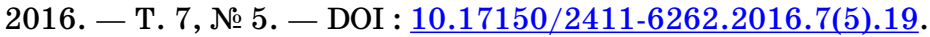

\section{Reference to article}

Pirmayev Ye. V. Types of court interpretation. Baikal Research Journal, 2016, vol. 7, no. 5.

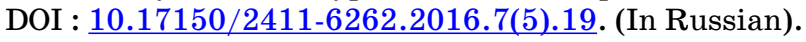

\section{Baikal Research Journal}

